Çukurova Üniversitesi Mühendislik Mimarlık Fakültesi Dergisi, 32(1), ss. 235-242, Mart 2017

Çukurova University Journal of the Faculty of Engineering and Architecture, 32(1), pp.235-242, March 2017

\title{
Veri Madenciliği Uygulamalarının ve Sezgisel Optimizasyon Algoritmalarının Yapım Yönetimindeki Yeri
}

\author{
Mümine KAYA KELEŞ ${ }^{1}$, Abdullah Emre KELEŞ*2 \\ ${ }^{1}$ Adana Bilim ve Teknoloji Üniversitesi, Mühendislik ve Doğa Bilimleri Fakültesi, Bilgisayar \\ Mühendisliği Bölümü, Adana \\ ${ }^{2}$ Adana Bilim ve Teknoloji Üniversitesi, Mühendislik ve Doğa Bilimleri Fakültesi, Inşaat Mühendisliği \\ Bölümü, Adana
}

Geliş tarihi: 20.01.2017_ Kabul tarihi: 14.03.2017

$\ddot{O} z$

Günümüzde her türlü kaynaktan sayıca fazla verinin elde edilmesi, bu verilerin anlamlı bir şekilde kullanılması ve yönetilmesi sorununu ortaya çıkarmaktadır. Bu sorunun çözümü için; anlamsız veri yığınlarından işe yarar verinin elde edilmesine ve bunların kullanılmasına olanak sağlayan istatistiki yöntemler ve optimizasyon metotları kullanılmaya başlanmıştır. Bu metotlardan en çok kullanılanları da veri madenciliği ve sezgisel algoritmalardır. Farklı disiplinlerde sıklıkla kullanılan bu metotlar inşaat sektöründe de yapı, hidroloji, geoteknik, yapım yönetimi, yapı malzemesi, mekanik gibi alanlarda da verilerin analizi için tercih edilmeye başlanmıştır. Bu çalışmada, ülkemizde ve dünyada hızla gelişsmekte olan inşaat sektörünün temelini oluşturan yapım yönetimi konusunda veri madenciliği ve sezgisel optimizasyon algoritmaları ile ilgili özellikle son 5 yıldaki literatür çalışmaları araştırılmış ve detaylı bir tablo üzerinde kronolojik olarak gösterilmiştir.

Anahtar Kelimeler: İnşaat sektörü, Sezgisel algoritmalar, Veri madenciliği, Yapım yönetimi

\section{The Place of Data Mining Applications and Heuristic Optimization Algorithms in Construction Management}

\begin{abstract}
In today's world, obtaining a lot of data from all kinds of sources reveals the problem of meaningful use and management of this data. Statistical methods and optimization methods are being used to obtain useful data from meaningless data stacks and to use them. The most common of these methods are data mining and heuristic algorithms. These methods, which are frequently used in different disciplines, have also begun to be preferred for the analysis of data in the construction sector in the fields of construction, hydrology, geotechnics, construction management, building materials, mechanics, ... etc. In this study, the literature studies, especially in the last 5 years, related to data mining and heuristic optimization algorithms on construction management which is the basis of rapidly developing construction industry in our country and world were examined and presented in chronological order on a table in detail.
\end{abstract}

Keywords: Construction sector, Heuristic algorithms, Data mining, Construction management

*Sorumlu yazar (Corresponding author): Abdullah Emre KELEŞ, aekeles@adanabtu.edu.tr 


\section{GíRiş}

Teknolojik gelişmeler her sektörde son yillarda büyük bir hızla artmaktadır. İnşaat sektörü de, yapı üretim sürecinde bu gelişmelerin beraberinde getirdiği yeniliklerden en çok etkilenen sektörlerden birisidir. Sayıca çok fazla değişkeni içerisinde bulunduran ve farklı iş birlikteliklerini ortaya çıkaran inşaat üretim süreci, inşaat yapım yönetiminin rastgele davranışlardan ziyade; planlı, sistemli ve uyum içinde çalışılan bir ortam oluşturma ve sürdürme sanatı olması sonucunu doğurmaktadır. $\mathrm{Bu}$ sebeple de inşaat yapım sektöründe üretilen verilerin sistemli şekilde depolanıp, ihtiyaca uygun ve etkin kullanımının sağlanabilmesi için bilgi teknolojilerinden faydalanılmasının önemli bir yer tuttuğu özellikle son yıllardaki çalışmalar ışı̆̆ında ortaya çıkmaktadır.

Veri Madenciliği; araştırılan konu ile alakalı, gözlem ve deneyler sonucunda elde edilen verilerden çok net olmayan ve önceden bilinmeyen ancak kullanışlı ve işe yarar olan bilginin çıkarılması işlemidir. Veri Madenciliği, genellikle veri içindeki gizli örüntüleri ortaya çıkarabilmek amacıyla kullanılmaktadır.

Veri Madenciliğinin uygulama alanlarına bakıldığında bankacılıktan pazarlamaya, eğitimden mühendislik uygulamalarına, inşaat sektöründen finans sektörüne, reklamcıllktan bilgisayar bilimlerine birçok sektörde ihtiyaç duyulan ve araştırılan bilgilere ulaşmak için kullanıldığı görülmektedir.

Sezgisel Algoritmalar, bilgisayar bilimlerinde sezgisel bir yaklaşımın problem çözümüne uygulandığ algoritmalar olup ilgili problemi çözme tekniğidir. Sonucun doğruluğunun kanitlanabilir olması sezgisel optimizasyon algoritmaları için önem arz etmemektedir. Genelde sezgisel optimizasyon algoritmaları ile iyiye yakın çözüm yolları elde edilmektedir. Çünkü bu algoritmalar, büyük boyutlu optimizasyon problemleri için, kabul edilebilir sürede optimuma yakın çözümler verebilen algoritmalardır.
Sezgisel Optimizasyon Algoritmalarının kullanılmasının en büyük avantajı; problemin çözüm zamanını azaltmasıdır. Bunu da en iyi çözümü aramaktan vazgeçerek sağlamaktadır. Genetik Algoritma [1,2], Karınca Kolonisi Optimizasyonu [3], Parçackk Sürü (Kuş Sürücü) Optimizasyonu [4], Yapay Ar1 Kolonisi [5], Benzetimli Tavlama Algoritması [6], Ateş Böceği Algoritmas1 [7] Sezgisel Optimizasyon Algoritmaları'nın başlıca örnekleridir.

Literatür incelendiğinde ise, veri madenciliği ve sezgisel optimizasyon algoritmaları özellikle son yıllarda inşaat sektöründe çalışanların da ilgi odağı haline gelmeye başlamıştır. Bilindiği üzere inşaat sektörü birçok disiplini içerisinde barındıran bir mühendislik bilimidir. Bu çalışma kapsamında, inşaat sektörünün temelini oluşturan yapım yönetimi alanında Türkiye'de ve dünya'da son 5 yılı kapsayan zaman diliminde gerçekleştirilmiş olan veri madenciliği ve sezgisel optimizasyon algoritmalarıyla ilgili literatürün taraması [8-31] yapılmış olup, detaylı bir şekilde sunumu gerçekleştirilmiştir. $\mathrm{Bu}$ vesileyle, bahsi geçen algoritma ve yöntemlerin inşaat proje yönetimindeki kullanım alanlarının geçmiş çalışmalarda hangi sorunu gidermeye yönelik araştııldığının ortaya konularak gelecek çalışmalara ışık tutması amaçlanmıştır.

\section{2. ÖNCEKİ CALIŞMALAR}

İnşaat Sektöründe veri madenciliği ve sezgisel optimizasyon algoritmalarının kullanılması ile ilgili çalışmalar, son yıllarda giderek artan bir hızla yaygınlaşmaya başlamıştır. Veri madenciliği ve bilgi teknolojileri inşaat sektöründe yeni kullanılmaya başlanıldığı için geçmiş yıllarda yapılan çok fazla çalışma bulunmamaktadır. İnşaat sektöründe son yıllarda yapılan çalışmalardan yapım yönetimi alanında yapılan çalışmalar bu bölümde incelenmektedir.

Bahadır ve Hanedaroğlu [8], çalışmalarında cam elyaf katkılı cephe kaplama elemanlarının 
pazarlanmasında teklif fiyatının Yapay Sinir Ağları yardımıyla tahmin edilmesi amaçlanmıştır.

Zhou [9] çalışmasında temel olarak, veri madenciliği ile bilgi yönetimi arasındaki ilişkiyi inceleyen bununla birlikte veri madenciliği algoritması üzerine araştırma yapan inşaat işletmelerinin kullandığı veri madenciliği uygulamalarına odaklanmıştır. İnşaat işletmelerinin veri madenciliği modeli ile birlikte Genelleştirilmiş Bulanıklaştırma Ağının (GFN) algoritmasını ve uygulamasını tasarlamış ve böylece veri madenciliği algoritmalarının en son araştırma sonuçlarına dayanan inşaat projesi verilerini karakterize etmiştir.

Haque ve Hasin [10] çalışmalarında, belirsiz koşullar altında bulanık zaman periyotları ile proje zaman-maliyet optimizasyonu problemini çözmek için daha gerçekçi bir yaklaşım geliştirmeyi amaçlamışlardır. Problemi modellemek için bulanık mantık teorisinde üçgensel bulanık sayılar ile bir kesme yöntemini ilgili çalışmada kullanmışlardır. Proje çizelgeleme probleminin NP (Nondeterministic Polynomial-time/Belirleyici Olmayan Karmaşıklık Zamanı ) zorluğu nedeniyle, bir arama aracı olarak Genetik Algoritma (GA) kullanılmıştır. Çalışmanın sonucunda çözüm, genetik algoritma parametrelerinin farklı kombinasyonları altında gerçekleştirilmiş ve sonuç analizinden sonra bu parametrelerin en iyi tahmin değerleri en yakın veya sürdürülebilir çözüm için bulunmuştur.

Kaya ve arkadaşları [11] çalışmalarında, inşaat işletmelerinde çalışan seramik işçilerinden anket yoluyla elde ettikleri veriler yardımıyla verimlilik değerlerini tahmin etmeye çalışmışlardır. İlgili çalışmada kullanılan nitelik olarak da değerlendirilen bu değerler; ekip sayıları, ekipteki kişilerin o iş tecrübeleri ve yaş ortalamalarıdır. İlgili çalışmalarında, ölçme yöntemleri kullanılarak elde edilmiş olan seramik verileri verimliliğin sınıflandırılarak kurallar çıkarılması vasıtasıyla seramik işlerinde yüksek verimliliğin girdilere göre nasıl sağlanabileceği konusu üzerine eğilmişlerdir.
Ahiaga-Dagbui ve Smith [12] çalışmalarında, inşaat sektöründe tahmin güvenilirliğini ve doğruluğunu artırmak için mevcut verileri karar verme destek sistemlerine dönüştürmek amaciyla veri madenciliğini önemli bir iş aracı olarak sunmaktadırlar. İlgili çalışmalarında, İngiltere'de 2004 ile 2012 y1lları arasında tamamlanan $1600 \mathrm{su}$ altyap1 projesi verilerini kullanarak, maliyet tahmini modellerini faktör analizi, optimal binning ve scree testleri gibi veri madenciliği yöntemlerinin bir kombinasyonu ile geliştirmişlerdir.

Zhou ve arkadaşları [13] çalışmalarında, inşaat iş programı optimizasyonunun alanını incelemek üzere geliştirilen yöntem ve algoritmaları ele almışlardır. İş programı optimizasyonu sorununu çözmek için geliştirilen algoritmaları üç yöntemle sınıflandırmışlardır: matematiksel, sezgisel ve meta-sezgisel. $\mathrm{Bu}$ yöntemlerin çeşitli çizelgeleme problemlerine uygulanması ilgili çalışmada tartışılmış ve gelecekteki araştırmalara etkileri yorumlanmıştır.

Aminbakhsh ve arkadaşları [14], çalışmalarında kesikli zaman-maliyet ödünleşim probleminin çözümünde yeni bir kuş sürüsü algoritması geliştirmişlerdir. $\mathrm{Bu}$ çalışma ile zaman ve maliyetin birlikte minimize edilmesini mümkün hale getirip optimum ve yakın-optimum zamanmaliyet çözümlemesini gerçekleştirerek sunmuşlardır.

Altun ve Akçamete [15], çalışmalarında inşaat projelerinin yönetiminde çok önemli bir yere sahip olan zaman ve maliyet problemlerinin sezgisel algoritmalarla modellenip çözümlenmesi üzerinde durmuşlardır. Zaman ve maliyet problemlerinin çözümünde sezgisel ve zeki algoritmalardan Yapay Arı Kolonisi Algoritmasını kullanmışlardır. Yapay Arı Kolonisi Algoritması kullanılarak elde dilen sonuçların gerçek değerlere daha yakın olduğu sonucuna varmışlardır.

Andaç ve Oral [16], çalışmalarında işçi verimliliklerinin tahmini için Yapay Arı Kolonisi 
Algoritmasını kullanarak elde ettikleri sonuçları sunmuşlardır.

Ebesek ve Yaman [17] çalışmalarında, yapım projelerinde kaynak dengeleme yani kaynak kısıtları altında çizelgeleme probleminin çözümüne yönelik meta-sezgisel optimizasyon algoritmalarından; genetik algoritmanın, diferansiyel gelişim algoritmasının, benzetilmiş tavlama algoritmasının, parçacık sürü optimizayonu algoritmasının ve karınca koloni optimizasyon algoritmasının optimum çözümler üretmesi ile ilgili çalışmaları incelemişlerdir. Çalışma sonucunda, meta-sezgisel algoritmaların kaynak dengeleme probleminde sıklıkla ve artan bir şekilde çalışıldığı sonucuna varmışlardır.

Giran ve arkadaşları [18], çalışmalarında bir inşaat firması için örnek bir veri ambarı uygulaması gerçekleştirmişlerdir. Eskiden yapılmış ve hala devam eden projelerden veriler elde edilmiştir. Çalışmanın amacı, etkili bir inşaat yönetiminin sağlanmasıdır.

Kasaplı ve Haznedaroğlu [19] çalışmalarında, içme suyu şebeke inşaatı maliyet tahminini Yapay Sinir Ağları tabanlı bir yöntem ve regresyon analizi yöntemini kullanarak gerçekleştirmişlerdir. Veri seti İller Bankası A.Ş. tarafindan onaylanan 58 adet proje verisinden oluşmaktadır. MS Excel Çözücü programı yardımıyla elde edilen sonuca göre tek katmanlı, 4 nöronlu ve sigmoid aktivasyon fonksiyonlu YSA modeliyle en iyi sonuç bulunabilmektedir.

Keleş ve Kaya [20] çalışmalarında ise inşaat sektöründe duvar ustası olarak çalışan işçilerden elde edilen demografik bilgilerle, çalışan verimliliğinin yükseltilmesi adına bir Veri Madenciliği yöntemi olan Birliktelik Kuralları çıkarmışlardır.

Yavuz ve arkadaşları [21], çalışmalarında bir karar destek modeli üzerinde durmuşlardır. $\mathrm{Bu}$ karar destek modeli veri zarflama analizi ile yapılandırılmıştır. Çalışmanın amacını, yapılı çevrede tasarım başarım değerlendirmesinin paydaşlar ile birlikte karar verme süreçlerini desteklemek oluşturmaktadır.

Yılmaz ve Dikbaş [22], kamu inşaat projelerinde yaşanan uyuşmazlıklara yönelik yazılı doküman arşivinin, bunlar dışında yargı kararları arşivinin hak talebi yönetiminde veri madenciliği ve metin madenciliği yöntemleri ile otomatik olarak sınıflandirılması konusunda çalışmışlardır. Dokümanlar sınıflandırıldıktan sonra bir karar destek modeli geliştirmişılerdir.

Durap ve Doğan [23] çalışmalarında, inşaat sektöründe kullanılan bilgilerin artması sebebiyle oluşan, belge takipsizliğini önlemek amaciyla elektronik bir sistemin oluşturulması gerektiği üzerinde durmuşlardır. Oluşturdukları belge takip sistemi ile en uygun malzeme ve yöntemin belirlenmesi ve kullanılması veri madenciliği yardımıyla sağlanmış, ilgili sistemin geri besleme ile eğitilmesi hedeflenmiştir.

Ahiaga-Dagbui ve Smith çalışmalarında [24], bir projenin ilk aşamalarında bütçesel karar vermede az bilgi ile doğru tahmini gerçekleştirmek için yapay sinir ağlarında parametrik olmayan topluluk modellemesi kullanarak 1600 tamamlanmış projeden aldığ modelleri geliştirmişlerdir. Çalışma sonucunda, 100 doğrulama öngörüsünün \%92'sinin projenin fiili nihai maliyetinin $\pm \% 10$ 'u dahilinde olduğu bulunurken, \%77'sinin fiili nihai maliyetin $\pm \% 5$ ' $\mathrm{i}$ dahilinde gerçekleştiği tespit edilmiştir.

Magalhães-Mendes [25] çalışmasında, bir proje için toplam maliyetin direkt ve dolaylı maliyetlerin toplamı olduğunu ve projenin en düşük maliyet ile tamamlanabilmesi için proje süresinin optimize edilmesi gerektiğini vurgulamıştır. İlgili çalışmada hem proje süresini hem de maliyetini objektif fonksiyona dahil etmeyi ve bir genetik algoritma kullanarak etkili bir sezgisel arama zamanlama kuralı geliştirmeyi amaçlamıştır.

Kaiafa ve arkadaşları [26], çalışmalarında, her bir etkinlik içinde birkaç kaynak-süre alternatifi değerlendiren, çok amaçlı kaynak kısıtlı 
zamanlama için bir optimizasyon yöntemi geliştirmişlerdir. Geliştirdikleri optimizasyon yöntemi, mevcut optimizasyon, kaynak dağılımı, proje süresinin aşılması ve günlük kaynak dalgalanmalarından kaynaklanan toplam maliyetin asgariye indirilmesini amaçlamaktadır. Optimizasyon için bir genetik algoritma kullanılmıştır. Algoritma birkaç test durumu ile test edilmiş ve sonuçlar Microsoft Project tarafından geliştirilenlerle karşılaştırılmıştır. Değerlendirme, önerilen algoritmanın üç amaçla ilgili olarak yeterli ve dengeli çözümler sağlayabileceğini ve bu çözümlerin ticari proje zamanlama yazılımı tarafindan sağlananlardan daha iyi olduğunu göstermektedir.

Keleş [27] çalışmasında, Türkiye'deki inşaat işletmelerinde çalışan şantiye şefi konumundaki liderlerle ve bu kişilerle birlikte çalışan astlarına çift taraflı bir anket uygulamıştır. Uygulanan bu anket sonrasında liderlik iki farklı açıdan belirlenmiştir. Liderlik modelleri belirlendikten sonra ise veri madenciliği yöntemlerinden birliktelik kural çıkarım yöntemi ile şantiye şeflerinin liderlikleri ile birlikte çalıştığı astlarının motivasyonları arasındaki ilişkiler belirlenmiştir.

Bayram ve Al-Jibouri [28] çalışmalarında, bina projelerinin maliyetlerini tahmin etmede tahmin yöntemlerinin etkinliğini araştırmışlardır. Bunun için de maliyet tahmini konusunda geleneksel olmayan, sezgisel optimizasyon ve veri madenciliğinde de kullanılan beş farklı güncel yöntemi bir arada kullanmışlardır. Bu beş yöntem; Çok Katmanlı Algılayıcı (MLP), Radyal Tabanlı Fonksiyon (RBF), Izgara Bölümleme Algoritması (GPA), Referans Sinıfı Öngörme (RCF) ve Regresyon Analizi (RA) yöntemleridir. Çalışmanın sonucunda Referans Sınıfi Öngörme (RCF) ve Regresyon Analizi (RA) yöntemlerinin diğer yöntemlere göre daha doğru ve gerçekçi tahminler ürettiği gözlenmiştir.

Atabay [29] çalışmasında, bir yapının Genetik Algoritma yöntemi kullanılarak optimizasyonunu yapmıştır. Optimizasyon sonucunda elde ettiği toplam maliyet ile geleneksel yöntem sonucunda elde ettiği toplam maliyet değerini bir örnek üzerinde karşılaştırmıştır. Taşıyıcı sistem tasarımında bir optimizasyon yöntemi kullanımının toplam yapı maliyetine etkisini araştırmıştır.

Koğ ve Yaman [30] çalışmalarında, e-ihale süreçlerinin etkinliğinin artırılmasına dair iş süreç modelleri oluşturulması ve bunların yapay zeka ve benzetim yöntemlerinden Petri Ağları yöntemi ile desteklenerek, işveren ve yüklenici açısından fayda optimizasyonunu gerçekleştirecek algoritmalara değinmişlerdir.

Bayram ve arkadaşları [31] çalışmalarında, yapay sinir ağı yöntemlerinden yaygın olarak kullanılan çok katmanlı algılayıcı (MLP) ve radyal tabanlı fonksiyon (RBF) ile elde edilen maliyet tahminlerini karşılaştırmayı amaçlamışlardır. Çalışmada, MLP ve RBF'nin sonuçları Birim Alan Maliyet Yöntemi sonuçları ile karşılaştırılmış ve birim alan maliyet yönteminin geçerliliği yorumlanmıştır. Her iki yapay sinir ağı yönteminin de birim alan maliyet yönteminden daha iyi performans gösterdiği, ancak radyal tabanlı fonksiyonun da çok katmanlı algılayıcıdan daha başarılı olduğu çalışma sonucunda tespit edilmiştir.

\section{MATERYAL VE METOT}

\subsection{Materyal}

$\mathrm{Bu}$ çalışma kapsamında Veri Madenciliği Algoritmaları ile Sezgisel Optimizasyon Algoritmalarının Türkiye'de yapılan yayınlar aracılığı ile yapım yönetimindeki yeri incelenmiştir. $\mathrm{Bu}$ sayede, bahsi geçen inceleme yöntemleri kullanılarak yapım yönetimi alanında yapılan yayınlar karşılaştırmalı olarak incelenerek gelecek çalışmalara ışı tutulması ve yön verilmesi amaçlanmıştır.

\subsection{Metot}

Türkiye'deki inşaat sektörünün özellikle yapım yönetimi bölümünün önemini vurgulamak amacıyla taranan literatürün detaylı bir şekildeki gösterimi Çizelge 1'de sunulmaktadır. 
Çizelge 1. Literatürün detaylı incelemesi

\begin{tabular}{|c|c|c|c|}
\hline Yapım Yönetimindeki Çalıșma & Yılı & VM/SA & Yöntem \\
\hline Bahadır ve Hanedaroğlu & 2012 & VM & Yapay Sinir Ağları \\
\hline Zhou & 2012 & VM & Genelleştirilmiş Bulanıklaştırma A $\breve{g}_{1}$ \\
\hline Kaya ve arkadaşları & 2013 & VM & Birliktelik Kuralları \\
\hline Ahiaga-Dagbui ve Smith & 2013 & VM & Yapay Sinir Ağları \\
\hline Zhou ve arkadaşları & 2013 & SA & $\begin{array}{l}\text { Fondahl Metodu, Yapısal Model, Genetik } \\
\text { Algoritma, Kuş Sürüsü Algoritması, Karınca } \\
\text { Kolonisi Algoritması }\end{array}$ \\
\hline Aminbakhsh ve arkadaşları & 2014 & SA & Kuş Sürüsü Algoritması \\
\hline Altun ve Akçamete & 2014 & SA & Yapay Ar1 Kolonisi Algoritmas1 \\
\hline Andaç ve Oral & 2014 & SA & Yapay Ar1 Kolonisi Algoritmas1 \\
\hline Ebesek ve Yaman & 2014 & SA & Meta-sezgisel Optimizasyon Algoritmaları \\
\hline Giran ve ark. & 2014 & VM & Veri Ambarı \\
\hline Kasaplı ve Haznedaroğlu & 2014 & VM & Yapay Sinir Ağları \\
\hline Keleş ve Kaya & 2014 & VM & Birliktelik Kuralları \\
\hline Yavuz ve arkadaşları & 2014 & VM & Veri Zarflama \\
\hline Y1lmaz ve Dikbaş & 2014 & $\mathrm{VM}$ & Sınıflandırma Algoritmaları \\
\hline Durap ve Doğan & 2014 & VM & $\begin{array}{l}\text { Yapay Sinir Ağları, Karar Ağaçları, En Yakın } \\
\text { K Komşu Algoritması, K-Ortalama, Kendi } \\
\text { Kendini Düzenleyen Haritalar } \\
\end{array}$ \\
\hline Ahiaga-Dagbui ve Smith & 2014 & VM & Yapay Sinir Ağları \\
\hline Magalhães-Mendes & 2015 & SA & Genetik Algoritma \\
\hline Kaiafa ve arkadaşları & 2015 & SA & Genetik Algoritma \\
\hline Keleş & 2016 & VM & Birliktelik Kuralları \\
\hline Bayram ve Al-Jibouri & 2016 & VM & $\begin{array}{l}\text { Çok Katmanlı Algılayıcı, Radyal Tabanlı } \\
\text { Fonksiyon, Izgara Bölümleme Algoritması, } \\
\text { Referans Sınıfı Öngörme ve Regresyon } \\
\text { Analizi }\end{array}$ \\
\hline Atabay & 2016 & SA & Genetik Algoritma \\
\hline Koğ ve Yaman & 2016 & SA & $\begin{array}{l}\text { Yapay Zeka ve Petri Ağları } \\
\text { yöntemi }\end{array}$ \\
\hline Bayram ve arkadaşları & 2016 & VM & $\begin{array}{l}\text { Çok katmanlı algılayıcı ve Radyal tabanlı } \\
\text { fonksiyon }\end{array}$ \\
\hline
\end{tabular}

\section{SONUÇLAR}

Literatür incelemeleri sonucunda özellikle ülkemiz inşaat sektöründe elde edilen hacimce ve sayıca fazla olan verilerin anlamlı ifadelere dönüştürülmesini sağlayan veri madenciliği uygulamalarına yönelik örneklerin azlığı dikkat çekmektedir. Oysaki bu çalışmada da vurgulandığı üzere, veri madenciliği ve sezgisel algoritmaların kullanılması ile inşaat sektörü gibi yeterince ham verinin elde edilebildiği bir sektörde ilgili çalışmaların yapılması vasıtasıyla daha yararlı sonuçlar elde edilebilecektir. $\mathrm{Bu}$ durum da, sektörde çoğu zaman farkında bile olunmayan pek çok rastgeleliğin sistemli çalışmalara bağlanması sebebiyle zaman kaybı, verimsizlik, etkinliğin düşük olması gibi olumsuzlukların azaltılabileceği düşünülmektedir.

İnşaat işletmelerinin ham verileri anlamlı hale getirebilmeleri için öncelikle elde etmiş oldukları mevcut verilerden neye ulaşmak istedikleri belirlenmeli ardından bu amaç doğrultusunda sınıflandırma, kümeleme, regresyon, birliktelik kuralı çıkarımı veya sezgisel algoritmaların kullanımı gibi çalışmalarla işletme yararına sonuçlar elde edilebilmektedir. Bundan sonraki çalışmalarda, bu verilerle inşaat ekonomisinden, 
şantiye yönetimine; deneysel çıkarımlardan pratik tüm inşaat uygulamalarına kadar veri madenciliğinin uygulanmaları ile sezgisel algoritmaların kullanımının artmasının tüm dünyada olduğu gibi ülkemiz inşaat sektörüne de olumlu yansıyacağı düşünülmektedir.

Çalışmanın diğer önemli sonucu, özellikle son yıllarda farklı disiplinlerde pek çok araştırmacı tarafindan yaygın şekilde kullanılan veri madenciliği metotları ile sezgisel algoritmaların kullanımının inşaat sektöründeki verilere daha sıklıkla uygulanabileceği ve yararlı sonuçlar elde edilebileceğidir. Ulaşılmak istenen amacın net şekilde belirlenmesi doğrultusunda şantiye ve ofislerden gelen işe yarar verilerin sistematiğe bağlanmasının ardından sektör temsilcileriyle paylaşılıp kullanılmasının inşaat ekonomisine de faydaları olacağı düşünülmektedir.

İnşaat sektörünün sayıca fazla ve çeşitli malzeme, işgücü, makine, donanım, gibi farklı kombinasyonlara sahip kaynaklarla yönetilmesi durumu, birbirinden farklı verilerin elde edilmesi sonucunu doğurmaktadır. Günümüz yoğun rekabet ortamında bu verilerin doğru analizlerinin sağlanması vasıtasıyla yönetilmesinin inşaat işletmelerinin yararına olacağı düşünülmektedir.

Tüm bunlarla birlikte, ülkemizde bugüne kadar yapılan ve bu çalışmayla sunulan yayınların inşaat sektöründe faaliyet gösteren işletmelere, çalışanlarına ve konuyla ilgili akademisyenlere ulaşmasının önemli olduğu düşünülmektedir. Veri madenciliği programları ile sistematiğe bağlanan verileri inşaat işletmelerinin yönetebilmesinin ve geleceği öngörebilmelerinin daha kolay olacağı ve bunun sonucu olarak, Türk inşaat sektöründe faaliyet gösteren işletmelerin daha isabetli yönetim stratejileri geliştirebileceği ve uzun vadeli fayda sağlayabileceği düşünülmektedir.

\section{KAYNAKLAR}

1. Beasley, D., Bull, D. R., Martin, R. R., 1993a. An Overview of Genetic Algorithms: Part 1, Fundamentals. University Computing, Vol.15(2), pp. 58-69, UK.
2. Beasley, D., Bull, D. R., Martin, R. R., 1993b. An Overview of Genetic Algorithms: Part 2, Research Topics .University Computing, Vol. 15(4), pp. 170-181, UK.

3. Colorni, A., Dorigo et V. Maniezzo, M., 1991. Distributed Optimization by Ant Colonies, actes de la première conférence européenne sur la vie artificielle, Paris, France, Elsevier Publishing, 134-142.

4. Kennedy, J., Eberhart, R., 1995. Particle Swarm Optimization. IV. s. 1942-1948.

5. Karaboga, D., 2005. An Idea Based on Honey Bee Swarm for Numerical Optimization, Technical Report-TR06, Erciyes University, Engineering Faculty, Computer Engineering Department.

6. Kirkpatrick, S., Gelatt, C. D., Vecchi, M. P., 1983. Optimization by Simulated Annealing. Science, New Series, Vol. 220, pp. 671-680.

7. Yang, X. S., 2008. Nature-Inspired Metaheuristic Algorithms. Luniver Press. ISBN 1-905986-10-6.

8. Bahadır, Y., Haznedaroğlu, F., 2012. Cephe Kaplama Elemanları Teklif Fiyatı Tahmininde Yapay Sinir Ağları (YSA) Kullanımı, 2. Proje ve Yapım Yönetimi Kongresi Bildiriler Kitabı, p. 146, İzmir.

9. Zhou, Y., 2012. Construction Knowledge Mining and Application of Generalized Fuzzy Network in Construction Decision Management, The Hong Kong Polytechnic University, Thesis.

10. Haque, K. M. A., Hasin, M. A. A., 2012. Genetic Algorithm for Project Time-cost Optimization in Fuzzy Environment. Journal of Industrial Engineering and Management, 5(2), 364-381.

11. Kaya, M., Keleş, A. E., Laptalı Oral, E., 2013. Construction Crew Productivity Prediction by Using Data Mining Methods, Procedia - Social and Behavioral Sciences, 141, 1249-1253.

12. Ahiaga-Dagbui, D. D., Smith, S. D., 2013. My Cost Runneth Over: Data Mining to Reduce Construction Cost Overruns, Procs $29^{\text {th }}$ Annual ARCOM Conference, 2-4 September 2013, Reading, UK, Association of Researchers in Construction Management, 559-568.

13.Zhou, J., Love, P. E. D., Wang, X., Teo, K. L., Irani, Z., 2013, A Review of Methods and 
Algorithms for Optimizing Construction Scheduling, Journal of the Operational Research Society, 64 (8), pp 1091-1105.

14. Aminbakhsh, S., Sönmez, R., Abbasi Iranagh, M., Rezvankhah, E., 2014. Kuş Sürüsü Optimizasyon Algoritması ile Kesikli ZamanMaliyet Ödünleşim Probleminin Çözümü, 3. Proje ve Yapım Yönetimi Kongresi Bildiriler Kitab1, p.34, Antalya.

15. Altun, M., Akçamete, A., 2014. Yapay Arı Kolonisi Algoritmasının Zaman-Maliyet Ödünleşim Problemlerine Uygulanması, 3. Proje ve Yapım Yönetimi Kongresi Bildiriler Kitab1, p.82, Antalya.

16. Andaç, M. S., Oral, E. L., 2014. Yapım İşlerinde Çalışan Verimliliğinin Yapay Arı Kolonisi Algoritması Kullanılarak Tahmini, 3. Proje ve Yapım Yönetimi Kongresi Bildiriler Kitabı, p.111, Antalya.

17. Ebesek, Ş., Yaman, H., 2014. Proje Ağlarında Kaynak Dengeleme Problemine Yönelik MetaSezgisel Optimizasyon Algoritmalarına Bakış, 3. Proje ve Yapım Yönetimi Kongresi Bildiriler Kitabı, p.61, Antalya.

18. Giran, Ö., Anbarcı, M., Türkakın, O. H., 2014. İnşaat Yönetiminde Veri Ambarlama ve Örnek Bir Veri Ambarlama Uygulamas1, 3. Proje ve Yapım Yönetimi Kongresi Bildiriler Kitabı, p.28, Antalya.

19. Kasaplı, K., Haznedaroğlu, F., 2014. İçme Suyu Şebekelerinde Yapay Sinir Ağları Tabanlı Maliyet Tahmini Ön Çalışması, 3. Proje ve Yapım Yönetimi Kongresi Bildiriler Kitabı, p.117, Antalya.

20. Keleş, A. E., Kaya, M., 2014, Duvar İnşa Edilmesinde Verimliliği Etkileyen Faktörlerin Apriori Veri Madenciliği Yöntemi Kullanılarak Analizi, XVI. Akademik Bilişim Konferansı, AB2014 Bildiriler Kitapçığ1, 831-836.

21. Yavuz, M., Doğan, S. Z., Kale, S., 2014. Veri Zarflama Analizi ile Tasarım Başarım Değerlendirmesi, 3. Proje ve Yapım Yönetimi Kongresi Bildiriler Kitabı, p.46, Antalya.

22. Yılmaz, İ. C., Dikbaş, A., 2014. İnşaat Sözleşmeleri Hak Talebi Yönetiminde Bir Veri Madenciliği Modeli, 3. Proje ve Yapım Yönetimi Kongresi Bildiriler Kitabı, p. 133, Antalya.
23. Durap, A., Doğan, Y., 2014. İnşaat Mühendisliği’nde Bilişim Kavramı ve Veri Madenciliği Algoritmalarıyla Bir Sistemin Oluşturulması. Akademik Bilişim Konferansları, Mersin.

24. Ahiaga-Dagbui, D. D., Smith, S. D., 2014. Dealing With Construction Cost Overruns using Data Mining, Journal Construction Management and Economics, Volume 32, 2014 - Issue 7-8: ARCOM Conference Issue.

25. Magalhães-Mendes, J., 2015. Multiobjective Optimization: Time-Cost Application in Construction, Congresso de Métodos Numéricos em Engenharia 2015, Lizbon.

26. Kaiafa, S., Chassiakos, A. P., A Genetic Algorithm for Optimal Resource-driven Project Scheduling, Procedia Engineering, Volume 123, 2015, Pages 260-267.

27. Keleş, A. E., 2016. İnşaat Projelerinde Şantiye Şeflerinin Liderliği ve Çalışan Motivasyonu İlişkisinin Veri Madenciliği ile Belirlenmesi, Çukurova Üniversitesi Fen Bilimleri Enstitüsü Doktora Tezi, Adana.

28. Bayram, S., Al-Jibouri, S., 2016. Efficacy of Estimation Methods in Forecasting Building Projects' Costs, Journal of Construction Engineering And Management-ASCE, vol.142.

29. Atabay, Ş., 2016, Yapım Maliyetinin Genetik Algoritma ile Optimizasyonunun Değer Mühendisliği Açısından İrdelenmesi, 4. Proje ve Yapım Yönetimi Kongresi, Eskişehir.

28. Koğ, F., Yaman, H., 2016, E-İhale Süreçlerinin Yapay Zekâ ve Benzetim Yöntemleri ile Optimizasyonu, 4. Proje ve Yapım Yönetimi Kongresi, Eskişehir.

31. Bayram, S., Öcal, M.E., Laptalı Oral, E., Atiş C.D., 2016. Comparison of Multi Layer Perceptron (MLP) and Radial Basis Function (RBF) for Construction Cost Estimation: The Case of Turkey, Journal of Civil Engineering And Management, Vol.22, pp.480-490. 